LICENÇA CC BY: Artigo distribuído sob os termos

Creative Commons, permite uso e distribuição irrestrita em qualquer meio desde que o autor credite a fonte original.

\title{
DA FINANCEIRIZAÇÃO DA EDUCAÇÃO: QUEM EDUCA O EDUCADOR?
}

THE FINACIALIZATION OF EDUCATION: WHO EDUCATES THE EDUCATOR? DE LA FINANCIARIZACIÓN DE LA EDUCACIÓN: ¿¿QUIÉN EDUCA EL EDUCADOR?

Mariléia Maria da Silva ${ }^{1}$

Márcia Luzia dos Santos²

${ }^{1}$ Doutora em Educação pela UFSC. Docente do Programa de Pós-Graduação em Educação da Universidade Estadual de Santa Catarina (UDESC), Florianópolis, SC, Brasil.

${ }^{2}$ Doutoranda em Educação pela Universidade Estadual de Santa Catarina (UDESC), Florianópolis, SC, Brasil.

Resumo: Este artigo problematiza a condução da formação continuada dos professores da Educação Básica na Rede Municipal de Ensino de Florianópolis (RMEF) por empresas privadas, mediante análise de dados de pesquisa de doutorado em andamento. O estudo fundase no materialismo histórico-dialético, e como procedimento metodológico utilizou-se o mapeamento de redes políticas, realizado a partir das empresas contratadas pelo município. Sustenta-se que a formação continuada dos professores da RMEF, orientada por entes privados, inscreve-se na denominada "privatização de novo tipo" (FALLEIROS; NEVES, 2015), usurpando o fundo público no contexto da financeirização do capital. Por conseguinte, refletem-se os limites da democratização da educação diante deste quadro, em que se promove a condução da formação dos professores por meio das parcerias público-privadas, difundindo valores e pressupostos político-ideológicos do empresariado.

Palavras-chave: Financeirização da educação; Formação continuada de professores; Parcerias público-privadas.

Abstract: This article discusses the conducting of professional development of teachers working in basic education in the Municipal Education System of Florianópolis (RMEF - its acronym in Portuguese) by private companies, through analysis of data from doctoral research in progress. The study is grounded in historical and dialectical materialism. The methodological procedure used was a mapping of political networks, based on companies contracted by the municipality. This article supports the view that the professional development of teachers of the RMEF, guided by private entities, is part of the so-called "new-type privatization" (FALLEIROS; NEVES, 2015), usurping the public fund in the context of financialization of capital. This has repercussions on the limits of democratization of education, in which professional development of teachers is promoted through public-private partnerships, disseminating the values and political and ideological assumptions of the business community. 
Keywords: Financialization of education; Professional development of teachers; Publicprivate partnerships.

Resumen: Este articulo problematiza la conducción de la formación continuada a los profesores de la enseñanza primaria en la Red de la Municipalidad de Enseñanza de Florianópolis (RMEF) por las compañías particulares, por análisis de datos de búsqueda del doctorado en proceso. El estudio se basa en el materialismo histórico-dialéctico, y como actuación metodológica se ha utilizado el control de las redes políticas, realizados desde las compañías contratistas por la municipalidad. Se sostiene que la formación continuada de los maestros del RMEF, guiados por entes privados, se inscriben en la nombrada "privatización del nuevo ejemplo" (FALLEIROS; NEVES, 2015), apoderándose del efectivo público en el ambiente de la financiarización del capital. Por lo tanto, se reflejan los límites de la democratización de la educación ante esta escena, en que se fomenta la conducción de la formación de los maestros por medio de los acuerdos oficiales y particulares, diseminando valores y presupuestos políticos-ideológicos de los empresarios.

Palabras-clave: Financiarización da la educación; Formación continuada de los profesores; Acuerdos oficiales-particulares.

\section{Introdução}

O presente artigo deriva de pesquisa de doutorado em andamento, que investiga a entrada de empresas privadas na formação continuada dirigida aos professores do Ensino Fundamental da Rede Municipal de Ensino de Florianópolis (RMEF). Procuramos explicitar de que maneira a atuação dessas empresas corrobora com novas formas de privatização, apropriando-se do fundo público no contexto da financeirização do capital. Nosso recorte temporal concentra-se no período de 2005 a 2016, durante a gestão do ex-secretário de educação Rodolfo Joaquim Pinto da Luz na Prefeitura Municipal de Florianópolis (PMF).

Compreender o processo de privatização que se instala na Educação Básica impõe apreender os imperativos do capital no cenário da financeirização, demarcado pelo processo de concentração de capitais, como Marx demonstrou mais especificamente no Livro III d'O Capital, ao investigar a dinâmica deste sistema no processo global da produção capitalista. Marx (2017) indica o surgimento da mercadoria 'capital', processo que demarca a fase que muitos autores, na atualidade, denominaram de "financeirização do capital".

Para melhor apreendermos esse conceito, apresentamos a síntese proposta por Chaves e Amaral (2016, p. 52, grifo no original), indicando que:

As transformações ocorridas no mercado financeiro mundial de liberação e desregulamentação dos fluxos financeiros, da interligação dos mercados, da criação de inovações financeiras (derivativos, securitização, contratos futuros etc.) e de fundos de investimentos institucionais, são denominadas por estudiosos de financeirização. 
O que observamos a partir do exposto é a hegemonia do capital portador de juros e do capital fictício na condução da política macroeconômica. Todavia, tratar da financeirização do capital não significa dizer que a base material da riqueza se deslocou da exploração do trabalho vivo, ao contrário, conforme Fontes (2010), as massas de capital monetário impulsionam o capital funcionante/produtivo e exacerbam as condições de extração do mais valor, impondo um grau de exploração muito mais severa à classe trabalhadora.

Contudo, esse processo de transformações econômicas com ênfase na liberalização dos mercados, na expansão do capital fictício (derivativos, securitização, contratos futuros, etc.) incluindo os ajustes neoliberais, deve ser compreendido como resposta à crise do capital, que apresentou seus sinais iniciais ao final dos anos de 1960 e se aprofunda na década seguinte. Tal crise foi promovida pela "desaceleração das taxas de crescimento nas principais economias do mundo, assim como nos problemas de manutenção das taxas de lucro" (CARCANHOLO, 2010, p. 02).

Mészáros assinala o caráter estrutural da crise e indica que "crises de intensidade e duração variadas são o modo natural de existência do capital: são maneiras de progredir para além de suas barreiras imediatas e, desse modo, estender com dinamismo cruel sua esfera de operação e dominação" (MÉSZÁROS, 2010, p. 69, grifo no original). Dessa forma, a crise é caracterizada pelo autor como estrutural por sua universalidade, seu alcance global, sua tendência a ser permanente, em vez de cíclicas - como as anteriores - e sua incontrolabilidade.

A grande contradição evidenciada por Mészáros (2010) é que a reprodução ampliada do capital não consegue atender as necessidades humanas, atingindo diretamente a classe trabalhadora, a força de trabalho, que é o cerne da criação do valor. Cada vez mais se reproduz miséria e se agudizam as disputas em torno de interesses antagônicos: direitos sociais e trabalhistas ou a manutenção das taxas de lucro. Essa relação conflituosa faz da crise estrutural do capital também uma crise de hegemonia.

Ao esclarecer o mecanismo das crises do capital, Iasi (2017a, p. 67) explicita as contradições entre capital-trabalho agravadas nesse contexto e afirma:

$\mathrm{Na}$ aparência, a crise é percebida pelos trabalhadores como um momento no qual o emprego está em baixa e o desemprego em alta, os salários se reduzem, o consumo despenca, os preços disparam, o crédito some, comércio e fábricas fecham. Analisando um pouco mais detidamente, no entanto, a crise se dá no auge do ciclo do capital, na superacumulação, ou seja, no momento em que o emprego está no máximo, as taxas de desemprego perigosamente baixas, o consumo superaquecido, a capacidade instalada à beira da plena utilização, o crédito abundante, por isso mesmo, as taxas de lucro em seu ponto mais baixo. A ideologia não tem o poder de 'inverter' a realidade, não se trata disso, mas de apresentar uma realidade invertida como se fosse natural.

Dessa forma, o autor destaca que o fenômeno que os trabalhadores identificam como crise, na verdade, constitui os mecanismos de saída da crise, indicando que a retomada da economia piora as condições de vida e emprego dos trabalhadores, liquida mercadorias, promove fusões, abre mercados e recompõe as taxas de lucro (IASI, 2017a). 
Portanto, diante do acirramento da crise, neste contexto da financeirização, cabe ao Estado a transferência da "riqueza social que se encontra sob a forma de fundo público" ao capital (GRANEMANN, 2012, p. 244). Nesta perspectiva, Iasi indica a existência de um aparelho governamental legislativo, repressivo, jurídico e ideológico, que permite ao Estado a defesa dos interesses da classe dominante. O autor afirma: "o conteúdo e a substância do Estado atual, do Estado que corresponde à sociedade atual capitalista, [...], são dados pela natureza das relações sociais de produção que cabe a ele garantir. Assim, o 'Estado atual' é o Estado burguês!' (IASI, 2017b, p. 125).

Portanto, o caráter de classe do Estado está intrinsecamente ligado às relações sociais de produção capitalista, e seu propósito é assegurar a dominação do capital sobre o trabalho. O Estado é reorganizado, refuncionalizado pela fração da classe hegemônica, que busca minimizar as crises do capital. Contudo, isso não quer dizer que tenhamos que abdicar das lutas travadas no âmbito do Estado, mas precisamos compreender seus limites. Diante de tal prerrogativa, Lênin (1986, p. 24) alerta:

Nós somos partidários da república democrática como sendo a melhor forma de governo para o proletariado sob o regime capitalista, mas andaríamos mal se esquecêssemos que a escravidão assalariada é o quinhão do povo mesmo na república burguesa mais democrática.

A assertiva de Lênin sublinha o quão urgente é a luta da classe trabalhadora na conjuntura que se apresenta. Neste intento, a já tão limitada democratização das políticas sociais encontra-se sob ameaça ainda maior diante do quadro esboçado para os próximos anos com a ascensão de Jair Messias Bolsonaro à presidência da República. A retomada da defesa deliberada do livre mercado - não que essa não estivesse na agenda dos governos petistas - agudiza a usurpação do fundo público pelo capital e a restrição das políticas sociais executadas diretamente pelo Estado. Desse modo, ressaltamos que o Estado se mantém presente, como nos governos anteriores, e tampouco se afastará da condição de subsidiário das políticas sociais, mas permanecerá mercadorizando-as, transferindo o fundo público, destinado a essas políticas, para o capital.

Destacamos, portanto, que essa é uma das estratégias de recomposição da taxa de lucro diante da crise. A abertura de mercados e a criação de novas mercadorias, que possibilitem ao capital recompor seu crescimento, concentram-se cada vez mais na expropriação dos direitos sociais conquistados pela classe trabalhadora. Nesse quadro, a Educação Básica é visualizada na conversão de um rol de produtos disponíveis à comercialização. Diante disso, evidenciamos nas últimas décadas a proliferação de medidas privatizantes que atingem esse nível de ensino.

Nessa conjuntura, em que os direitos sociais estão sob risco intenso e iminente, somos impelidos a fazer pesquisas que examinem a fundo a entrada dos entes privados na condução dos serviços públicos sob o predomínio do capital rentista.

A fim de explicitar melhor essa questão, organizamos o texto em tela em três tópicos, além desta parte introdutória. No primeiro tópico apresentamos a discussão 
acerca da democratização sob a lógica do empresariamento da Educação Básica. Assinalamos que a partir das crises do capital se estruturam reformas e medidas que viabilizaram a entrada dos entes privados na educação pública por meio das parcerias público-privadas, instituindo um processo de mercadorização e privatização da Educação Básica. Essa estratégia permitiu ao capital o assenhoramento do fundo público e a inserção das formulações do empresariado na formação continuada dos docentes e na educação da classe trabalhadora, corroborando com a tese apresentada por Neves (2005) de que está sendo colocada em prática uma "nova pedagogia da hegemonia".

No segundo tópico, destacamos as empresas e os institutos de natureza privada sem fins lucrativos que se inseriram na formação continuada dos professores por intermédio da Secretaria Municipal de Educação de Florianópolis (SMEF).

Por fim, nos limites deste artigo, destacamos a empresa Joint Venture ModernaAvalia e sua integração no Grupo Prisa e Santillana, compondo um grande conglomerado empresarial espanhol com atuação em diversos países. Nesse tópico também refletimos sobre os limites da democratização da Educação Básica diante do processo de "privatização de novo tipo" (FALLEIROS; NEVES, 2015).

\section{Parcerias público-privadas na educação: Quando a democratização se dá pela lógica do empresariamento}

O contexto descrito anteriormente dá esteio e nos impele a compreender a Educação Básica no contexto de refuncionalização do Estado diante da imperativa necessidade do capital de recomposição das taxas de lucro. Nesse sentido, ao discorrer sobre a financeirização da economia brasileira, Paulani (2017, p. 30) evidencia que:

\footnotetext{
A economia brasileira, evidentemente, faz parte dela [financeirização], inicialmente de forma passiva, quando foi vítima da chamada 'crise da dívida externa' nos anos 1980, depois de forma ativa, quando tomou as providências, a partir de meados dos anos 1990, para seu ingresso na era da financeirização como 'potência financeira emergente' ou, nos nossos termos, como 'plataforma internacional de valorização financeira'.
}

Segundo a autora, foi nesse contexto que os governos de Fernando Henrique Cardoso (FHC) (1995-2002), Lula da Silva (2003-2010) e Dilma Rousseff(2011-agosto/2016) instituíram "a adoção de um receituário macroeconômico agressivamente voltado para o benefício da riqueza financeira, baseado na austeridade fiscal e em taxas reais de juros absurdamente elevadas, frequentemente as campeãs do mundo" (PAULANI, 2017, p. 30).

Granemann (2017) indica a transferência de parte significativa das riquezas sociais - materializadas pelo Estado como fundo público - ao capital já a partir da crise iniciada em meados de 1960 e agravada em 1970. A autora afirma que, mais recentemente, a crise capitalista iniciada em 2007-2008 consolida essa tendência de apropriação do fundo público pelo privado. Essa transferência de riqueza efetuada pelos que trabalham em 
prol exclusivamente do capital aprofunda o caráter classista do Estado, consolidando-o cada vez mais como o Estado do capital.

Dessa forma, Granemann esclarece que não interessa excluir por completo as políticas sociais, mas transformá-las em serviços, e adverte:

\begin{abstract}
As políticas sociais, ao se metamorfosearem em serviços, caminharam em direção a uma nova condição: se tornaram valores de troca, mercadorias. As novas mercadorias, além de continuar colaborando com a reprodução das relações de produção capitalistas, cumpririam novas funções básicas: 1. constituem espaços alternativos para o investimento de capitais; 2 . liberam porções significativas do fundo público para a formação de superávits necessários, por exemplo, para o pagamento da dívida pública e para o socorro perpétuo do Estado aos grandes capitais em risco de falência e quebra (GRANEMANN, 2017, p. 236, tradução nossa).
\end{abstract}

Isso posto, estabelecemos como marco significativo a reforma do Estado iniciada no governo de Fernando Collor de Mello (1990-1992), do então Partido da Reconstrução Nacional (PRN), tendo seu ápice nos mandatos de Fernando Henrique Cardoso (FHC), do Partido da Social Democracia Brasileira (PSDB), e aprofundada nos governos petistas subsequentes, Lula da Silva e Dilma Rousseff.

Tais reformas viabilizaram a implementação de modelos de gestão empresarial na condução das políticas sociais, orientadas pelas concepções presentes no Plano Diretor da Reforma do Aparelho do Estado (PDRAE) (BRASIL, 1995). Altera-se, a partir de então, o entendimento de que as políticas sociais deveriam ser dirigidas exclusivamente pelo Estado, abrindo-se espaço para entidades caracterizadas como públicas, de caráter não estatal, ou privadas. Como estratégia para viabilizar a entrada de entes privados na gestão dos serviços públicos, instituíram-se a privatização, a terceirização e a publicização (PERONI; ADRIÃO, 2004).

Diante desse quadro, compreendemos que as múltiplas alterações na legislação educacional, no decorrer das reformas, corroboraram com a instalação da lógica privatista na educação. Sejam elas operacionalizadas por meio da Lei de Diretrizes e Bases da Educação Nacional (LDBEN) n 9394/96, de 20 de novembro de 1996 (BRASIL, 1996), que institucionalizou a gestão por resultados, prevendo avaliação externa; a política de descentralização via municipalização da Educação Básica, deixando a cargo de municípios a condução da Educação Infantil e Fundamental, sem que tivessem as devidas condições para executá-las; a descentralização financeira, instituída por meio da política de fundos, como o Fundo de Manutenção e Desenvolvimento do Ensino Fundamental e de Valorização do Magistério (FUNDEF) ${ }^{1}$ e o Fundo de Manutenção e Desenvolvimento da Educação Básica e de Valorização dos Profissionais da Educação (FUNDEB $)^{2}$, que atende toda a Educação Básica, da Creche ao Ensino Médio. Esses fundos contribuíram substancialmente para que os municípios contratassem setores privados para a condução das políticas de gestão, apostilamentos, compra de vagas em creches particulares, dentre outros (ADRIÃO et al., 2010).

Esse rearranjo legislativo que permitiu ao Estado abrir espaço ao privado para gerir as políticas sociais, no caso da educação, ainda foi acrescido da gestão centrada nos 
resultados, viabilizada principalmente pelas avaliações em larga escala e pela divulgação do Índice de Desenvolvimento da Educação Básica (IDEB). A ênfase nos resultados em conjunto impôs novas demandas à Educação Básica, dentre essas, a formação continuada de professores a qual passa, por vezes, a ser conduzida por entes privados.

Nessa perspectiva de gerenciamento da educação, apresentada pelo setor empresarial, evidenciamos o interesse pela formação dos futuros trabalhadores centrada na preparação para o trabalho simples, e expõe a centralidade dada aos professores na condução do processo. Todavia, essa centralidade se limita à execução pragmática do prescrito, desconsiderando qualquer possibilidade de autonomia de ensino. Dessa forma, temos os professores retratados como despreparados, malformados, responsabilizados pela divulgada "crise da educação", e demonizados, conforme preconiza o descomedido projeto Escola sem Partido.

Assim, podemos caracterizar o avanço de empresas privadas na formação continuada dos professores como uma ação coordenada de reconversão docente ao proposto pelo empresariado. Pois, conforme Evangelista e Shiroma (2007, p. 537), "[...] há um controle político e ideológico sobre o magistério que envolve sua formação e atuação profissional". As autoras ainda indicam um processo de "[...] desintelectualização dos professores como contraface de seu controle".

Nesse sentido, temos observado a inserção da classe empresarial na formulação das políticas educacionais inaugurando um promissor setor de vendas de serviços para a educação pública (FREITAS, 2012). Compreendemos que a entrada de entes privados aprofunda a privatização de novo tipo na Educação Básica. A esse respeito, Melo et al. (2015, p. 41) afirmam que essa nova modalidade de privatização se caracteriza por um "[...] processo organicamente articulado de difusão e legitimação de preceitos das organizações privadas nas instituições públicas".

Essa lógica empresarial também é apontada por Martins (2015) ao indicar a prevalência do chamado "terceiro setor" adentrando à esfera pública e operando na difusão de valores e comportamentos políticos próprios do projeto hegemônico burguês. $\mathrm{O}$ autor assinala que esses novos sujeitos coletivos, que se autodenominam como "terceiro setor", se colocam numa instância entre o Estado e o mercado, visando realçar o protagonismo da "iniciativa privada com sentimento público" (2015, p.74). Martins define, portanto, que a partir dessa ideia, a classe empresarial se coloca como capaz de contribuir com a solução dos problemas presentes na condução da educação pública.

Nessa configuração, do público sendo gerido em meio aos valores do intitulado "terceiro setor", outra questão preponderante é a estratégia de reposição da hegemonia burguesa por meio da Educação Básica, que se materializa na presença de uma nova pedagogia da hegemonia (NEVES, 2005). A entrada de institutos e de fundações empresariais oferecendo pacotes variados de serviços educativos, além de escancaradamente desencadear novas formas de apropriação do fundo público, coaduna 
com a formação de trabalhadores forjados nessa sociabilidade. Na sanha de impor seus valores e manter-se hegemônico, o empresariado tem difundido a atuação pedagógica pautada em competências e habilidades, assim como no empreendedorismo e no desenvolvimento das habilidades socioemocionais. Todas essas vertentes 'pedagógicas' procuram conformar o futuro trabalhador àquilo que é inerente ao capitalismo, a desigualdade social, responsabilizando-o individualmente pelo fracasso.

Diante do exposto, compreendemos que a lógica privada tem atravessado a formação docente no município de Florianópolis por meio da inserção de empresas e institutos. Assim, as parcerias público-privadas para a formação continuada dos docentes integram o circuito de valorização de capitais, pois mercadoriza a Educação Básica e a fazem convergir com a alteração dos ajustes delineados por organizações multilaterais $(\mathrm{OM})$, pelos órgãos de governo e pelas burguesias brasileira e internacional. Nesse sentido, como afirmam Melo et al. (2015, p. 43), operaram-se alterações na formação docente inicial e continuada, pois,

[...] o empresariado brasileiro integrou-se cada vez mais organicamente à formulação das políticas para qualificação da força de trabalho do projeto dos organismos internacionais, subsidiou a formulação das políticas educacionais nacionais e desenvolveu estratégias para o redirecionamento do seu projeto político-pedagógico no âmbito da educação municipal, distrital e estadual.

A partir dessa proposição, o professorado torna-se estratégico como difusor da "nova pedagogia da hegemonia". Neves e Sant'Anna (2005), ao caracterizá-la, evidenciam que essa tem como propósito redefinir o padrão de politização fordista e atuar no sentido de "repolitizar a política". Para tanto, "[...] a nova pedagogia da hegemonia estimula a pequena política em detrimento da grande política, propiciando, contraditoriamente, à classe trabalhadora a realização da grande política da conservação" (NEVES, SANT'ANNA, 2005, p. 35).

No âmbito da "grande política da conservação", na promoção de conformismos e na apropriação do fundo público, entendemos a entrada e a permanência do empresariado na formação docente no município de Florianópolis. Nesse sentido, nossa pesquisa possibilitou a apreensão de inúmeras redes políticas que se formam envolvendo as empresas contratadas pela RMEF. Tais redes comportam uma variedade de aparelhos privados de hegemonia da burguesia (GRAMSCI, 1987,1989), se reúnem em torno de objetivos comuns, difundem suas ideias e atuam na formulação de políticas públicas para a educação. Colocam-se por meio de institutos, fundações, organizações sociais, órgãos governamentais e demais entidades da sociedade civil, como os portadores da "resolução" dos problemas educacionais. Dessa racionalidade, apresentada pelo empresariado, decorre um repertório de produtos educacionais vendidos às secretarias de educação e às escolas como "soluções inovadoras" e possibilidades de melhorar a qualidade do ensino.

Nesse decurso, formam-se redes sociais que criam, vendem produtos e mobilizam políticas. Nessas redes, encontramos empresas das mais diversas origens e que comercializam uma variedade de produtos que não se restringem ao campo educacional. O Estado 
assume um papel relevante na constituição das redes, tanto na elaboração e na viabilização das políticas, quanto na construção de espaços para que sejam instauradas. Isso se dá pelos reordenamentos jurídicos - instituição de novas leis - ou pela inauguração de novos mercados, disponibilizando o fundo público para a compra dos materiais e dos serviços.

Fica claro o imbricamento entre as organizações empresariais e estatais. E, sob esse aspecto, destacamos a afirmação de Gramsci (1989, p. 87) acerca do Estado: "[...] Estado é todo o complexo de atividades práticas e teóricas com as quais a classe dirigente justifica e mantém não só o domínio, mas consegue obter consentimento ativo dos governados [...]". Compreendemos, portanto, o Estado como difusor da ideologia da classe dominante, mantenedor da hegemonia burguesa pela dominação/coerção da classe trabalhadora e pela direção/consenso promovido no seio dessa mesma classe.

Nessa perspectiva, apreendemos as redes políticas em torno da educação pública como estratégia de organização e manutenção da classe dirigente na recomposição da taxa de lucro, utilizando-se do fundo público, reordenando sua hegemonia e direcionando a educação da classe trabalhadora e a conduta dos professores às necessidades atualizadas do capital.

\section{Formação continuada dos docentes no circuito da valorização do valor}

Apresentaremos neste tópico as empresas e os institutos de natureza privada sem fins lucrativos que estiveram presentes na formação continuada dos docentes do Ensino Fundamental da Prefeitura Municipal de Florianópolis. Conforme determinamos na introdução deste artigo, nosso recorte temporal se estabelece na gestão do ex-secretário municipal de educação Rodolfo Joaquim Pinto da Luz, que esteve à frente da secretaria por um período de doze anos (2005-2016), exercendo três mandatos consecutivos em governos distintos, inicialmente no antigo Partido do Movimento Democrático Brasileiro (PMDB), atual MDB, e posteriormente no governo do Partido Social Democrático (PSD).

Obedecendo a este recorte, mapeamos as instituições a partir da investigação dos contratos firmados com a PMF. Contudo, para melhor compreendermos a inserção dessas entidades na educação pública, como no mercado educacional, e quais relacionamentos travam com outras empresas, organizações da sociedade civil, órgãos do Estado e OM, nos ocupamos de investigar seus websites. Esta análise permitiu descrever o envolvimento das empresas e dos institutos pesquisados em redes políticas de atuação nacional e internacional, que procuram estabelecer diretrizes para a formação continuada dos professores e para a forma e o conteúdo da educação pública.

A pesquisa possibilitou apreender que essas redes políticas comportam uma variedade de aparelhos privados de hegemonia da classe empresarial, que se reúne em torno de objetivos comuns, difunde suas ideias e atua no sentindo de formular políticas 
públicas para a educação. Diante do apresentado, procuramos demonstrar como a lógica privada tem penetrado na formação docente no município de Florianópolis, e defender que essa inserção compõe nova forma de privatização e apropriação do dinheiro público.

Evidenciamos a contratação de sete empresas, que venderam produtos e se inseriram na formação continuada dos professores do Ensino Fundamental da RMEF; e dois institutos, que difundiram sua ideologia sob o argumento da filantropia. No ano de 2008, houve a contratação da Empresa Planneta Educação Gráfica e Editora Ltda., com acordo renovado nos anos de 2010 e 2014, cujo objeto estipulado era o serviço de consultoria para capacitação de técnicos e conselheiros municipais de educação (FLORIANÓPOLIS, 2008, 2010a, 2014a). Em 2010, com contratos renovados nos anos de 2012, 2014, foram adquiridos serviços da Empresa VEZ - Instituto UniBrasil para Desenvolvimento da Ciência e Cultura - para implantação de sistema educacional visando ao atendimento dos alunos na Rede, nas áreas do $1^{\circ}$ ano ao $5^{\circ}$ ano do Ensino Fundamental de nove anos (FLORIANÓPOLIS, 2010b, 2012b, 2014b). Ainda em 2010 foi firmado acordo com a Empresa Meritt Informação Educacional Ltda., com renovações nos anos de 2011 e 2012. Essa forneceu serviços técnicos especializados da avaliação da RMEF - prova Floripa ${ }^{3}$ e provinha Brasil (FLORIANÓPOLIS, 2010c, 2011, 2012a).

As empresas anteriormente arroladas contaram com o pagamento via recursos próprios do município ou vinculados ao Ministério da Educação, como os disponibilizados pelo Fundo Nacional de Desenvolvimento da Educação (FNDE) e salário-educação. Ao elencar as empresas contratadas, destacamos as que se utilizaram das verbas oriundas do acordo de empréstimo n 3079/0C - BR, entre o município de Florianópolis e o Banco Interamericano de Desenvolvimento (BID) ${ }^{4}$ realizado no ano de 2014 (BID, 2014).

No ano de 2015 foi firmado acordo com o Centro de Políticas Públicas e Avaliação da Educação (CAEd) para elaboração, aplicação, processamento, análise e devolutiva de resultados da Prova Floripa nas disciplinas de língua portuguesa e matemática para todos os alunos, de todos os anos (séries) do Ensino Fundamental, nos anos de 2014 a 2018 (FLORIANÓPOLIS, 2015a). Nesse mesmo ano, a RMEF firmou contrato com a Universidade do Sul de Santa Catarina (UNISUL) para elaborar as Matrizes Curriculares do Ensino Fundamental e Educação de Jovens e Adultos (FLORIANÓPOLIS, 2015b). Ainda em 2015 foi contratada a Empresa Mind Lab do Brasil Comércio de Livros Ltda., sendo adquirida licença de uso da metodologia Mind Lab, com fornecimento de material didático -jogos de raciocínio (FLORIANÓPOLIS, 2015c). E, por fim, obedecendo ao recorte temporal delimitado, no ano de 2016 foi a vez da Empresa Joint Venture Moderna-Avalia, havendo a contratação de plataforma digital de conteúdos, "Soluções Educacionais", para os componentes curriculares de língua portuguesa, matemática, ciências e língua estrangeira - inglês -, para estudantes do Fundamental II (FLORIANÓPOLIS, 2016).

Além das empresas descritas, apresentamos os institutos de natureza privadas e sem fins lucrativos que participaram da formação docente sem representar custos para a 
PMF. Como não tivemos acesso a contrato ou termo de adesão, os dados foram obtidos por meio das entrevistas realizadas e da pesquisa nos websites dos institutos. Destacamos o Instituto Tim, atuando na formação docente por meio do projeto "TIM Faz Ciência", que se anuncia como iniciativa do Instituto TIM dirigida a professores e estudantes de $4^{\circ}$ e $5^{\circ}$ anos do Ensino Fundamental (INSTITUTO TIM, 2017); e o Instituto Natura, que disponibilizou o "Projeto Trilhas", "[...] voltado à formação de professores que trabalham com crianças em fase de alfabetização e desejam aproximar a literatura das práticas de sala de aula" (INSTITUTO NATURA, 2017).

Compreendemos aatuação desses dois institutos noâmbito do 'filantrocapitalismo', cujas "[...] doações estão destinadas a investimentos rigorosamente escolhidos e que dê retorno nos fins propostos" (GAWRYSZEWSKI; MOTTA; PUTZKE, 2017, p. 737). A esse respeito, Ball indica:

O que há de 'novo' em 'nova filantropia' é a relação direta de 'doar' por 'resultados' e envolvimento direto de doadores em ações filantrópicas e comunidades políticas. Ou seja, um movimento de doação paliativa à desenvolvimentista. [...] Os 'novos' filantropos querem ver impactos e resultados claros e mensuráveis de seus 'investimentos' de tempo e dinheiro (BALL, 2014, p. 121-122).

Conjugando a compra direta de produtos com o filantrocapitalismo, o que se apresenta é a privatização da Educação Básica e o assenhoramento do fundo público pelo capital. Perseguindo essa prerrogativa, ao somarmos o valor gasto com as empresas contratadas no período de 2008-2016, que se envolveram na formação docente, chegamos ao total de $\mathrm{R} \$ 12.176 .280,17$ (doze milhões, cento e setenta e seis mil, duzentos e oitenta reais e dezessete centavos). Não conseguimos estipular o percentual que esse valor representa ao município de Florianópolis, já que não temos a receita total da RMEF, contudo indicamos que parte do fundo público está sendo destinado à compra de serviços educacionais, ou seja, sendo colocado no circuito de valorização do valor. Assim, salientamos o aumento no investimento público na contratação de empresas a partir do contrato firmado pelo BID.

Embora o Estado sempre disponibilizasse recursos para a contratação de serviços de infraestrutura, após a reforma de 1990, com o aparato jurídico reestruturado e a formulação do consenso em torno do papel da "solidária" sociedade civil, outros serviços passaram a ser contratados pelo ente público. Diante desse pressuposto, inferimos que a política de "melhoria da educação pública", celebrada no acordo entre a PMF e o BID, está sendo utilizada para incrementar o capital, uma vez que uma parte desses recursos é investida nas parcerias público-privadas. 


\section{A forma e o conteúdo da educação básica na bolsa de valores}

Nos limites deste texto não apresentaremos todas as redes que abarcam as empresas que venderam formação docente à Secretaria Municipal de Educação de Florianópolis. Assim, destacaremos a rede em que se insere a Empresa Joint Venture Moderna-Avalia, cujo contrato com a RMEF foi celebrado no ano de 2016. A empresa é composta pela Editora Moderna Ltda. e pela Avalia Qualidade Educacional Ltda. e forneceu plataforma digital de conteúdos, a Plataforma SmartLab. O termo Joint Venture enuncia a fusão de empresas tratando-se de uma modalidade de investimento definida como "Capital Venture" cujos recursos financiam expansões empresariais para impulsionar os negócios a novos níveis no mercado, estimular novas transações.

Ao investigarmos a rede política da qual faz parte a Joint Venture Moderna-Avalia, chegamos a um de seus administradores, Sérgio Gustavo de Aguiar Quadros, que atua no ramo da comunicação com o El País Brasil Agência de Notícias e Publicidade Ltda. Quadros é também presidente do Grupo Santillana Brasil, que é anunciada como "[...] braço editorial do grupo PRISA, líder em meios de comunicação, entretenimento e educação nas línguas espanhola e portuguesa. Presente em 22 países, a Santillana iniciou suas atividades no Brasil em 2001, ao adquirir as editoras Moderna e Salamandra" (SANTILLANA, 2018).

Quanto ao Grupo Prisa, observamos sua atuação em áreas que comportam edição, educação, formação, jornalismo, rádio, audiovisual, dentre outras. No ano de 2010, foi noticiado pelo jornal O Globo o acordo entre o Grupo Prisa e a americana Liberty Acquisition Holdings, que anuncia a ampliação de capital. Desde então, o Prisa passa a ter suas ações cotadas na bolsa de Madri e Nova Iorque. Ao visualizarmos o capital social do Grupo nos últimos anos, constatamos uma valorização crescente das ações do Prisa, que garantiu sua expansão no mercado. Ademais, vale ressaltar que no contexto de financeirização do capital torna-se comum a fusão de empresas sob o controle de grupos proprietários que captam recursos em bolsas de valores (FONTES, 2010).

A rede política evidenciada indica que a Educação Básica, nas mais variadas formas, passa a integrar plataformas de valorização do capital. No caso assinalado, indicamos como mercadoria disponibilizada no mercado a formação continuada docente. Shiroma (2011) aponta o encorajamento presente nos fóruns e nos documentos oriundos das OM para que se articulem redes sociais no setor educacional. A autora define as redes sociais como "[...] um conjunto de pessoas e/ou organizações que se agregam com interesse comum, contribuem para a produção e disseminação de informações, criam canais de comunicação e estimulam a participação da sociedade" (SHIROMA, 2011, p. 18). Contudo, assinala o interesse dos formuladores internacionais de política em afirmar as redes como estratégia de consenso entre quem estabelece as políticas e quem as aplica. 
Assim, compreendemos o entrelaçamento entre o Estado, os $\mathrm{OM}$ e os grandes conglomerados internacionais, como o Grupo Prisa e Santillana. Nesse contexto, o trânsito de intelectuais da burguesia atua no sentido de instituir um sistema de governança em torno da educação pública. Tal governança não tem relação apenas com a preparação da força de trabalho, mas também como importante mecanismo de conformação das massas ao projeto do capital.

Nessa perspectiva, destacamos que a Joint Venture Moderna-Avalia trabalhou a partir do ano de 2017 na formação docente, treinando os professores dos anos finais do Ensino Fundamental para a utilização da Plataforma Digital SmartLab e assessorandoos diretamente nas escolas. Essas ações respaldam as considerações de Peroni (2013, p. 30), ao afirmar que "[...] o privado acaba influenciando e definindo o público, não mais apenas na agenda, mas na execução das políticas, definindo o conteúdo e a gestão da educação, com profundas consequências para a democratização da educação".

Evidenciamos que essas empresas se entrelaçam em redes que vendem as anunciadas "soluções educacionais" à educação pública. Nesse contexto, a formação continuada procura reconverter o professor para a adoção dessas ditas "soluções" que são apresentadas pelas instituições como inovação na Educação Básica. O professor deve, portanto, tornar-se aquele que concretiza as demandas do mercado educacional por meio da utilização e do incentivo ao uso, principalmente, das tecnologias.

Isto posto, ressaltamos a proposição apresentada por Vale (2017, p. 05) ao se referir ao processo de financeirização da educação: "Estes conglomerados educacionais representam um processo de centralização e concentração de capital, mas também de oligopolização educacional/institucional em curso significativo e perigoso". Pois, segundo a autora, a existência do capital financeiro nesse processo modifica a natureza da mercadorização da educação. Inferimos que a Educação Básica se encontra imersa no processo de financeirização do capital. Isto está evidenciado também pela atuação de grandes conglomerados empresariais com abertura de capital na bolsa de valores, haja vista a forma de atuação do Grupo Prisa, que se caracteriza como empresa de capital aberto e atua por meio da fusão de capitais buscando se valorizar.

Nesse decurso, o fundo público torna-se a principal garantia de valorização de capitais. Diante da financeirização, a mercadorização da Educação Básica indica o prejuízo para a democratização desse nível de ensino, uma vez que se aprofundam as formas de gestão privada nos serviços públicos. O que, de fato, temos consubstanciado é a democratização da educação da classe trabalhadora sob a lógica do empresariado, deixando o horizonte da emancipação humana cada vez mais distante. Todavia, como afirma Tonet (2013, p. 279), "[..] a emancipação humana pode e deve ser posta como o fim mais alto da humanidade". Isso nos leva a salientar a necessidade e a urgência das lutas pela democratização do ensino e pela direção dos pressupostos da educação pública, ainda mais nesses tempos de intensificação do obscurantismo. 


\section{Considerações}

Compreender o processo de privatização da Educação Básica impõe a necessidade de não perder de vista o contexto histórico em que as relações capitalistas se estabelecem. Diante da financeirização do capital, com o acirramento de suas crises, vivenciamos a apropriação da riqueza social como forma de amenizar seus efeitos. Por isso apontamos que as parcerias público-privadas, estabelecidas no serviço público, conformam mais um mecanismo de apropriação do fundo público, pois acarretaram novas formas de financiamento social ao setor privado. Destacamos, portanto, que o avanço do capital sobre a Educação Básica assume as mais variadas estratégias, e evidenciamos a formação continuada dos professores, conduzida por empresas privadas, como um dos meios pelos quais a Educação Básica passa a ser inserida no processo de privatização. Nessa seara, incluímos os reordenamentos legislativos que permitem a compra de produtos e serviços ou se ocupam da isenção de impostos às instituições. Por esses meios, os entes privados apropriam-se dos impostos que deveriam garantir direitos sociais aos trabalhadores. Conferimos ao Estado um papel relevante na constituição das redes, tanto na elaboração das políticas quanto na construção de espaços para que sejam instauradas.

Nesse sentido, nos remetemos às ponderações de Shiroma e Evangelista (2014, p. 04), ao assinalarem que: "[...] o Estado não ficou mínimo e o governo não foi substituído, entretanto, constitui um importante nó nas redes. As organizações estatais não agem nem definem isoladamente as políticas e as redes não se limitam às fronteiras nacionais".

Isto posto, ao mapearmos as empresas e os institutos de natureza privada sem fins lucrativos que adentraram a formação docente na RMEF, alcançamos infindáveis redes políticas nas quais se envolvem tanto organizações do Estado, OM, instituições privadas e grandes conglomerados internacionais. Redes que não apenas vendem produtos e se apropriam do fundo público, mas disseminam novos modos de agir, de pensar, ou seja, criam novos nexos psicofísicos nesta fase de financeirização do capital e da degradação das condições de vida. Em nossa compreensão, essas redes e grandes empresas comportam-se como aparelhos privados de hegemonia da classe dominante.

Nessas condições, a educação torna-se uma das estratégias hegemônicas de difusão e propagação desses novos valores. Não que essa não assumisse esse caráter em tempos anteriores na sociedade capitalista, todavia nos cumpre desvelar quais nexos passam a ser forjados sob o domínio do empresariado. Assim, compreendemos que um dos objetivos das políticas apresentadas pelo Estado, em parceria com as $\mathrm{OM}$ e com o empresariado e suas redes, é que os professores sejam reconvertidos a intelectuais orgânicos e agentes de coesão social em prol da hegemonia do capital. O horizonte proposto é a adaptação dos futuros trabalhadores às demandas do setor produtivo. E é justamente nesta conjuntura, em meio às relações sociais travadas a partir dos interesses do capital internacional e nacional, que procuramos evidenciar os limites dos processos de 
democratização da Educação Básica. A luta por essa democratização precisa ultrapassar as meras barreiras do acesso - ainda que essas tenham sido promovidas de maneira limitada, mesmo diante da propalada universalização da educação - e percorrer o duro caminho das pedras na disputa pela direção da educação pública, considerando as necessidades da classe trabalhadora e assegurando uma formação sólida que conteste a forma hegemônica, assim aniquilando os interesses do mercado sob pena de apenas democratizarmos a lógica do capital.

\section{Referências}

ADRIÃO, T. et al. A simbiose entre as prefeituras paulistas e o setor privado: Tendências e implicações para a política educacional local. In: Anais da Anped. 2010. Disponível em: http://33reuniao. anped.org.br/internas/ver/trabalhos-gt05. Acesso em: 28 jul. 2017.

BALL, S. J. Educação Global S.A.: novas redes políticas e o imaginário neoliberal. Ponta Grossa: UEPG, 2014.

BANCO INTERAMERICANO DO DESENVOLVIMENTO (BID). Contrato de empréstimo $\mathbf{n}^{\circ} \mathbf{3 0 7 9 /}$ OC-BR entre o município de Florianópolis e o Banco Interamericano do Desenvolvimento. Florianópolis, 2014.

BRASIL. Ministério da Educação. Lei de Diretrizes e Bases da Educação Nacional n 9.394/96, de 20 de dezembro de 1996. Estabelece as diretrizes e bases da educação nacional. Brasília: MEC, 1996.

. Ministério da Administração da Reforma do Estado (MARE). Plano Diretor da Reforma do Aparelho de Estado. Brasília, 1995. Disponível em: http://www.bresserpereira.org.br/documents/ mare/planodiretor/planodiretor.pdf. Acesso em: 03 out. 2018.

CARCANHOLO, M. D. Crise econômica atual e seus impactos para a organização da classe trabalhadora. In: Aurora, ano IV, número 6, p.1-10, ago. de 2010. Disponível em: http://www. marilia.unesp.br/Home/RevistasEletronicas/Aurora/1\%20CARCANHOLO.pdf. Acesso em: 19 jun. 2018.

CHAVES, V. L. J.; AMARAL, N. C. Política de expansão da educação superior no Brasil - O Prouni e o Fies como financiadores do setor privado. In: Educação em Revista, Belo Horizonte, v. 32, n. 04, p.205-225, out. 2016.

EVANGELISTA, O.; SHIROMA, E. O. Professor: protagonista e obstáculo da reforma. Revista Educação e Pesquisa, v. 33, n. 3, p. 531-541, set./dez. 2007.

FALLEIROS, I.; NEVES, L. M. W. Mudanças na natureza da educação básica. In: MARTINS, A. S.; NEVES, L. M. W. (Orgs.). Educação básica: tragédia anunciada? São Paulo: Xamã, 2015. p. 103158.

FLORIANÓPOLIS. Contrato $\mathbf{n}^{\circ}$ 1045/EDUC/BID/2016. Joint Venture Moderna-Avalia composta por Editora Moderna Ltda. e Avalia qualidade educacional Ltda. Florianópolis, 2016.

Contrato $n^{\circ}$ 1021/EDUC/BID/2015. Mind Lab do Brasil Comércio de Livros Ltda. Florianópolis, 2015c. 
2008.

Contrato n 389/EDUC/2008. Planneta Educação Gráfica e Editora Ltda. Florianópolis,

Contrato no 389/EDUC/2008 - $3^{\circ}$ Termo aditivo. Planneta Educação Gráfica e Editora Ltda. In: Diário oficial eletrônico do município de Florianópolis: n. 334.07 de outubro de 2010. Florianópolis, 2010a. Disponível em: http://portal.pmf.sc.gov.br/arquivos/diario/ pdf/07_10_2010_18.38.16.e3aac2658610980ccbcb162fb74f1fd6.pdf. Acesso em: 05 abr. 2018. 2014a.

. Contrato n 680/EDUC/BID/2014. Planneta Educação Gráfica e Editora Ltda. Florianópolis,

Contrato n 100/EDUC/2010. VEZ - Instituto UniBrasil para Desenvolvimento da Ciência e Cultura. Florianópolis, 2010b.

. Contrato n 91/EDUC/2012. VEZ - Instituto UniBrasil para Desenvolvimento da Ciência e Cultura. Florianópolis, 2012b.

. Contrato $n^{\circ}$ 469/SME/2014. VEZ - Instituto UniBrasil para Desenvolvimento da Ciência e Cultura. Florianópolis, 2014b.

Contrato no 146/EDUC/BID/2015. Universidade Federal de Juiz de Fora - Centro de Políticas Públicas e Avaliação da Educação (CAEd). Florianópolis, 2015a.

Contrato n $^{\circ}$ 791/EDUC/BID/2015. Universidade do Sul de Santa Catarina - UNISUL. Florianópolis, 2015b.

Extrato do contrato n 326/EDUC/2010. Meritt Informação Educacional Ltda. In: Diário oficial eletrônico do município de Florianópolis: n. 218. 22 de abril de 2010. Florianópolis, 2010c. Disponível em: http://portal.pmf.sc.gov.br/arquivos/diario/pdf/ 22_04_2010_17.34.11. fffd8edd2d2ff235d4f874407c33a10b.pdf. Acesso em: 05 abr. 2018.

Extrato do contrato n 357/EDUC/2011. Meritt Informação Educacional Ltda. In: Diário oficial eletrônico do município de Florianópolis: n. 470. 05 de maio de 2011. Florianópolis, 2011. Disponível em: http://www.pmf.sc.gov.br/arquivos/diario/pdf/05_05_2011_18.29.27. f9bb05bf6cfbf8fe8b2223623d5458be.pdf. Acesso em: 05 abr. 2018.

. Extrato do contrato no 745/EDUC/2012. Meritt Informação Educacional Ltda. In: Diário oficial eletrônico do município de Florianópolis: n. 844. 05 de novembro de 2012. Florianópolis, 2012a. Disponível em: http://www.pmf.sc.gov.br/arquivos/diario/pdf/08_11_2012_18.54.34.0c474 55b123c772ed31b9dfd169547bd.pdf. Acesso em: 05 abr. 2018.

FONTES, V. O Brasil e o capital-imperialismo: teoria e história. $3^{a}$ ed. Rio de Janeiro: EPSJV/ Editora UFRJ, 2010.

FREITAS, L. C. Os reformadores empresariais da educação: da desmoralização dos magistérios à destruição do sistema público de educação. In: Educação e Sociedade [online]. 2012, v. 33, n. 119, p. 379-404. Disponível em: http://www.scielo.br/scielo.php?pid=\$010173302012000200004 \&script=sci_abstract\&tlng=pt. Acesso em: 27 maio 2017.

GAWRYSZEWSKI, B.; MOTTA, V. C.; PUTZKE, C.K. Gestão privada de escolas públicas da Educação Básica: um novo mercado sob a tutela do Estado. In: Práxis Educativa, Ponta Grossa, v. 12, n. 3, p. 728-748, set./dez. 2017 Disponível em: <http://www.revistas2.uepg.br/ index.php/ praxiseducativa. DOI:10.5212/PraxEduc.v.12i3.003.

GRAMSCI, A. A questão meridional. Rio de Janeiro: Paz e Terra, 1987. 
1989.

Maquiavel, a Política e o Estado Moderno. $7^{a}$ ed. Rio de Janeiro: Civilização Brasileira,

GRANEMANN, S. Fundos de pensão e a metamorfose do "salário em capital". In: SALVADOR, E. et al. (Orgs.). Financeirização, fundo público e política social. São Paulo: Cortez, 2012. p. 243-260.

Monetarización y financiarización de las políticas sociales: expresiones del neodesarrollismo? In: FÉLIZ, M.; PINASSI, M. O. (Org.). La farsa neodesarrollista - y las alternativas populares en América Latina y el Caribe. $1^{a}$ ed. Buenos Aires: Ediciones Herramienta, v. 01, 2017, p. 233-243.

IASI, M. L. A crise do capital: a era da hipocrisia deliberada. In:

Política, Estado e ideologia na trama conjuntural. São Paulo: ICP - Instituto Caio Prado Jr., 2017a. p. 59-84.

A atualidade da revolução soviética e a questão do Estado. In: Política, Estado e ideologia na trama conjuntural. São Paulo: ICP - Instituto Caio Prado Jr., 2017b. p. 113-145.

INSTITUTO TIM. TIM Faz Ciência. 2017. Disponível em: https://institutotim.org.br/ project/. Acesso em: 04 jul. 2018.

INSTITUTO NATURA. Trilhas. 2017. Disponível em: http://www.institutonatura.org.br/ iniciativa/ trilhas/. Acesso em: 19 fev. 2017.

LÊNIN, V. O Estado e a Revolução. Tradução: Aristides Lobo. São Paulo: HUCITEC, 1986.

MARTINS, A. S. Formulações da classe empresarial para a formação Humana: da educação política à educação escolar. In: Revista Contemporânea de Educação, vol. 10, n. 20, julho/dezembro, 2015.

MARX, K. O Capital: crítica da economia política. Livro III: o processo global da produção capitalista. Tradução: Rubens Enderle. 1ª ed. São Paulo: Boitempo, 2017.

MELO, A. A. S. et al. Mudanças na educação básica no capitalismo neoliberal de terceira via no Brasil. In: MARTINS, A. S.; NEVES, L.M. W. (Orgs.). In: Educação básica: tragédia anunciada? São Paulo: Xamã, 2015, p. 23-44.

MÉSZÁROS, I. Das crises cíclicas à crise estrutural. In: A atualidade histórica da ofensiva socialista. São Paulo: Boitempo, 2010, p. 69-98.

NEVES, L. M. W. (Org.). A nova pedagogia da hegemonia: estratégias do capital para educar o consenso. São Paulo: Xamã, 2005.

NEVES, L. M. W.; SANT'ANNA, R. Introdução: Gramsci, o Estado educador e a nova pedagogia da hegemonia. In: NEVES, L. M. W. (Org.). A nova pedagogia da hegemonia: estratégias do capital para educar o consenso. São Paulo: Xamã, 2005. p. 18-39.

PAULANI, L. M. Não há saída sem a reversão da financeirização. In: Estudos Avançados, v. 31 (89), p. 29-35, 2017.

PERONI, V. M. V. A Privatização do público: implicações para a democratização da educação. In: - (Org.) Redefinições das fronteiras entre o público e o privado: implicações para a democratização da educação. Brasília: Liber Livro, 2013. p. 09-32.

PERONI, V. M. V.; ADRIÃO, T. Reforma da ação estatal e as estratégias para a constituição do público nãoestatal na educação básica brasileira.In:Anais da Anped.2004. Disponível em: http://27reuniao. anped.org.br/?_ga=2.79630292.1124126624.1501336700-1888206714.1475164430. Acesso em: 28 jul. 2017. 
SANTILLANA. Santillana. 2018. Disponível em: https://www.gruposantillana.com.br/web/ gruposantillana/santillana. Acesso em: 26 mar. 2018.

SANTOS, M. L. dos. Intensificação do trabalho docente: contradições da política de economizar professores. 2013. 240f. Dissertação (Mestrado em Educação) - Programa de Pós-Graduação em Educação, Universidade Federal de Santa Catarina. Florianópolis, SC, 2013.

SHIROMA, E. O. Redes sociais e hegemonia: apontamentos para o estudo de política educacional. In: AZEVEDO, M. L. N.; LARA, A. M. B. (Orgs.). Políticas para a educação: análises e apontamentos. Maringá: EDUEM, 2011. p. 15-38.

SHIROMA, E. O.; EVANGELISTA, O. Estado, capital e educação: reflexões sobre hegemonia e redes de governança. In: Revista Educação e Fronteiras On-Line, Dourados/MS, v.4, n.11, p.21-38, mai./ago. 2014. Disponível em: <http://ojs.ufgd.edu.br/index.php/educacao/article/view/4359>. Acesso em: 12 abr. 2018.

TONET, I. Educação, cidadania e emancipação humana. 2.ed. Maceió: EDUFAL, 2013.

VALE, A. A. "Nem parece banco": as faces da financeirização da Educação Superior no Brasil. In: $5^{\circ}$ Encontro Internacional de Política Social $12^{\circ}$ Encontro Nacional de Política Social. ES, Brasil, 5 a 8 de jun. de 2017. Disponível em: http://periodicos.ufes.br/EINPS/ article/view/16588. Acesso em: 4 jul. 2018.

Artigo recebido em: 03/12/2018 Aprovado em: 21/03/2019

\section{Contato para correspondência:}

Mariléia Maria da Silva.E-mail: marileiamaria@hotmail.com

1 O FUNDEF foi instituído pela Emenda Constitucional no 14, de setembro de 1996, e regulamentado pela Lei no 9.424, de 24 de dezembro do mesmo ano, e pelo Decreto no 2.264, de junho de 1997.

2 O Fundeb substituiu o Fundef, que vigorou de 1997 a 2006 . O Fundeb está em vigor desde janeiro de 2007 e se estenderá até 2020.

3 A Prova Floripa é um instrumento avaliativo elaborado pela Secretaria Municipal de Educação de Florianópolis, que objetiva aferir a qualidade da educação das escolas da RMEF (SANTOS, 2013).

4 O contrato de empréstimo no 3079/0C - BR destina-se ao Projeto de Expansão e Aperfeiçoamento da Educação Infantil e do Ensino Fundamental no Município de Florianópolis, cujo valor corresponde ao montante de US\$58.860.000,00 (cinquenta e oito milhões, oitocentos e sessenta mil dólares). Todavia, o custo total do programa, estimado em quantia equivalente a US\$118.430.000,00 (cento e dezoito milhões, quatrocentos e trinta mil dólares), compromete a PMF a fornecer, oportunamente, para a completa e ininterrupta execução do programa, o equivalente a US\$59.570.000,00 (cinquenta e nove milhões e quinhentos e setenta mil dólares) (BID, 2014). 